\title{
Three-body abrasive wear of fine pearlite, nanostructured bainite and martensite
}

\author{
S. Das Bakshi ${ }^{1 a}$, P. H. Shipway ${ }^{\mathrm{b}}$, H. K. D. H. Bhadeshia ${ }^{\mathrm{a}}$ \\ ${ }^{a}$ Materials Science and Metallurgy, University of Cambridge, U.K \\ ${ }^{b}$ Mechanical, Materials and Manufacturing, University of Nottingham
}

\begin{abstract}
The abrasive wear of three metallurgical structures with radically different hardnesses have been investigated for the same steel. The particular steel concerned is a recent innovation capable of generating extremely fine distributions of crystals. The austenite in the alloy nevertheless has the capability of uniformly transforming into extremely fine pearlite, nanostructured bainite, and plate martensite. It is found that although the abrasion rates and wear coefficients are not very different for the three states, the mechanisms of abrasion are quite different. We report detailed characterisation experiments together with comparisons with commercially available steels subjected to identical tests.
\end{abstract}

Keywords: three-body abrasion, carbide-free bainite, electron microscopy

\section{Introduction}

An high-carbon steel has recently been developed that can be transformed into a mixture of bainitic ferrite and retained austenite that is so fine that Vickers hardness values in excess of $600 \mathrm{kgf} \mathrm{mm}^{-2}$, strength exceeding $2000 \mathrm{MPa}$ and toughness levels $40 \mathrm{MPa} \mathrm{m}^{1 / 2}$ can be achieved routinely in bulk samples which are large in all three dimensions [1, 2]. The material following transformation is referred to as "nanostructured" because the individual platelets of bainitic ferrite have thicknesses in the range 20-40 $\mathrm{nm}$ and one of the largest densities of interfacial area per unit volume reported for a bulk material which is now produced commercially in the thousands of tonnes [3]. The application of the steel in armour is fully commercialised and there are programmes for applications to shafts, bearings and wear-resistant components.

There have been a number of previous studies on the wear of carbide-free bainitic steels, some of which were reviewed by Bhadeshia [4], but the interest here is on the nanostructured form ${ }^{2}$. The dry sliding wear resistance of nanostructured bainite has been studied by Wang et al. [5]; who found that the austenite in the vicinity of the sliding

\footnotetext{
${ }^{1}$ Corresponding author: Tel $\quad+44-1223-334336, \quad$ E-mail address: sd444@cam.ac.uk/subhankar.dasbakshi@gmail.com

${ }^{2}$ The term 'nanostructure' has unfortunately become a generic reference to a wide range of grain and precipitate structures, to the extent that it is often misleading and taken to represent structures far coarser than the adjective would imply [3]. We define it to represent cases where the interfacial area per unit volume, $S_{V}$, is large enough to make the governing length scale $\bar{L}=2 / S_{V}$ comparable to the narrower dimensions of carbon nanotubes, i.e., of the order 20-50 nm.
} 
surface decomposes under the influence of high shear strains developed, resulting in the formation of an even finer structure with grains of ferrite only a few nanometers in size. They concluded that the formation of this fine microstructure resulted in slight increase in wear resistance. In another study, nanostructured carbide-free bainite was produced in a case-carburised layer, and it was demonstrated that the structure outperformed somewhat harder martensite [6]. The differences in behaviour were small under low applied loads (where mild wear dominated with debris being predominantly in the form of oxide). However, under higher loads, the wear debris was shown to be primarily metallic in nature (with delamination flakes being $>10 \mu \mathrm{m}$ in size); under these conditions, the bainitic structure (with its higher strain to fracture) was able to resist delamination more effectively than the martensitic structure, resulting in a higher wear resistance being exhibited. A similar conclusion was reached when comparing the bulk form of the nanostructured bainite, which again had a lower sliding wear-rate than harder martensite [7]. The dry rolling-sliding wear of series of steels said to contain carbide-free bainite has been reported recently [8] ( a high slip of $\sim 5 \%$ was used in the test programme); here, the carbide-free bainitic steels were shown to exhibit significantly lower rates of wear $(\sim 50 \%)$ than a steel with a lower bainitic microstructure, even at similar hardness levels and this was attributed to the desirable combination of hardness and toughness of the carbide-free bainitic microstructure. However, the metallography reported is not of sufficient resolution to establish the presence of a nanostructure, and the higher transformation temperatures used are consistent with coarser forms of bainite. In contrast, the alloy studied here has had many levels of detailed characterisation, as reviewed elsewhere $[2]$.

The present work was motivated from observations of the severe wear of steel at the oil sands mines in Alberta, Canada, particularly in earth moving operations involving large transporters. In light of the benefits that have been observed in sliding wear performance of carbide-free bainitic steels, a study was initiated to examine first the capability of the new steel to resist dry abrasion. The nanostructured bainite contains only two phases, bainitic ferrite and retained austenite, generated by isothermal transformation at $200^{\circ} \mathrm{C}$; it achieves the vast majority of its strength because of the closely packed interfaces between these phases $[9,10]$. The structure is therefore unusual and it was felt that it would be useful to study also the pearlitic and untempered martensitic states in the same steel. For example, untempered high-carbon martensitic steels can achieve a maximum hardness of about $800 \mathrm{kgf}^{-\mathrm{mm}^{-2}}$ [11] but the dissolved carbon tends to make the martensite extremely brittle and the pearlitic state is interesting because the interlamellar spacing in this kind of steel can be made to be extremely fine at ordinary cooling rates [12, 13].

\section{Experimental Procedures}

The chemical composition of the steel is listed in Table 1, produced from a 5.9 tonnes steel melt using vacuum induction melting and electro-slag refining, followed by continuous casting into $150 \mathrm{~mm}$ diameter billets. Samples for abrasion test were machined as rectangular blocks of size $25 \times 60 \times 14 \mathrm{~mm}$ from the centre of the billets, using electrodischarge machining. About $1 \mathrm{~mm}$ was removed from each of the broad faces with 240 grit wet $\mathrm{SiC}$ abrasive paper to avoid any damage due to discharge machining. These specimens were then heat treated to obtain the desired structures as described in Table 2. 
Table 1: Chemical composition (wt\%) of the steel

\begin{tabular}{cccccccccccccc}
\hline $\mathrm{C}$ & $\mathrm{Mn}$ & $\mathrm{P}$ & $\mathrm{S}$ & $\mathrm{Si}$ & $\mathrm{Al}$ & $\mathrm{Cu}$ & $\mathrm{Cr}$ & $\mathrm{Mo}$ & $\mathrm{V}$ & $\mathrm{Co}$ & $\mathrm{Sn}$ & $\mathrm{Nb}$ \\
0.83 & 2.28 & 0.011 & 0.008 & 1.9 & 0.044 & 0.12 & 1.44 & 0.24 & 0.11 & 1.55 & 0.019 & 0.023 \\
\hline
\end{tabular}

Table 2: Hardness values (HV30) following specified heat treatments

\begin{tabular}{lll}
\hline Sample & Heat Treatment & HV30 $/ \mathrm{kgf}_{-} \mathrm{mm}^{-2}$ \\
\hline Pearlite & $930{ }^{\circ} \mathrm{C} 1 \mathrm{~h}$, cooled $0.1^{\circ} \mathrm{C} \mathrm{s}^{-1}$ to $550^{\circ} \mathrm{C}$, held for $4 \mathrm{~h}$, air-cooled & $378 \pm 9$ \\
Bainite & $930{ }^{\circ} \mathrm{C} 1 \mathrm{~h}$, air cooled to $200{ }^{\circ} \mathrm{C}$, held for 10 days, air cooled & $622 \pm 13$ \\
Martensite & $930^{\circ} \mathrm{C} 1 \mathrm{~h}$, air cooled & $739 \pm 7$ \\
\hline
\end{tabular}

The heat treated samples were characterised using scanning electron (Jeol 5800 LV) and transmission electron (Jeol $200 \mathrm{CX}$ ) microscopy depending on the resolution required. In the former case, the ground and polished samples were etched with 2 volume $\%$ nital; for transmission microscopy, slices approximately $200 \mu \mathrm{m}$ thick were slit, from which discs of $3 \mathrm{~mm}$ diameter were electro-discharge machined. The discs were ground down to $50 \mu \mathrm{m}$ thickness using $\mathrm{SiC}$ abrasive paper and foils prepared by electropolishing at $-4^{\circ} \mathrm{C}$ in a mixture of $5 \%$ perchloric acid, $15 \%$ glycerol and $80 \%$ methanol by volume.

\subsection{Abrasion tests}

Three-body abrasion tests were conducted broadly in accord with standard practice [14], using the parameters listed in Table 3. The non-standard values of the rotational speed and total number of wheel revolution were chosen to ensure appreciable wear of the samples. Samples were ground using 400 grit $\mathrm{SiC}$ papers prior to the experiments, which utilised silica sand with an average particle size of $300 \mu \mathrm{m}$ as the abrasive medium. The equipment and the abrasive sand used are illustrated schematically in Fig. 1(a) and (b) respectively. The sand flow rate and rotation speed of the wheel were kept constant throughout each experiment. The test was stopped after every 2700 rotations for $10 \mathrm{~min}$ in order to prevent excessive heating of the sample and the rubber wheel. The specific wear rate and wear coefficient were determined from weight loss data.

Surface profiles and roughness were measured using vertical-shift interferometry on a WYCO optical profilometer. X-ray diffraction was carried out both before and after the abrasion tests. Unabraded samples in a polished and etched condition were examined in a Philips PW1820 vertical diffractometer with unfiltered $\mathrm{Cu}-\mathrm{K}_{\alpha 1}$ radiation of wavelength $\lambda=1.5418 \AA$. Abraded sample were studied using X-rays without any surface preparation following abrasion. Diffraction was carried out in a continuous scanning mode over a range of $2 \theta=10-156^{\circ}$ with a step size of $0.03^{\circ}$ and dwell time of $11 \mathrm{~s}$ per step. 


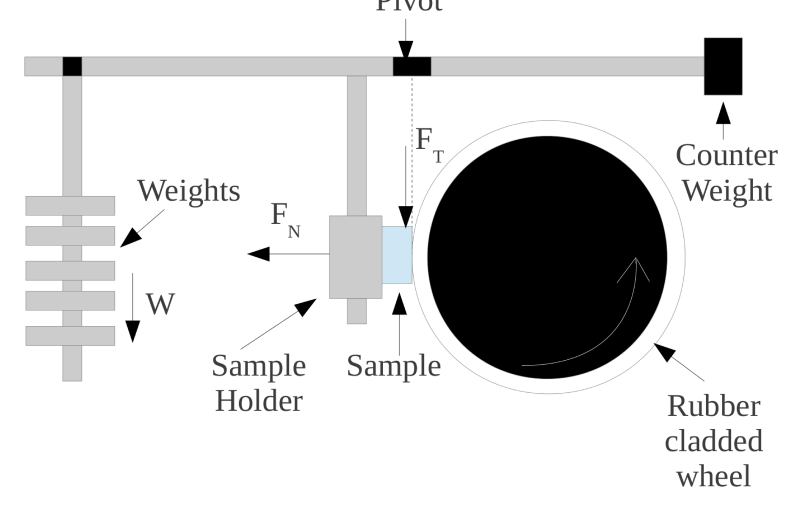

(a)
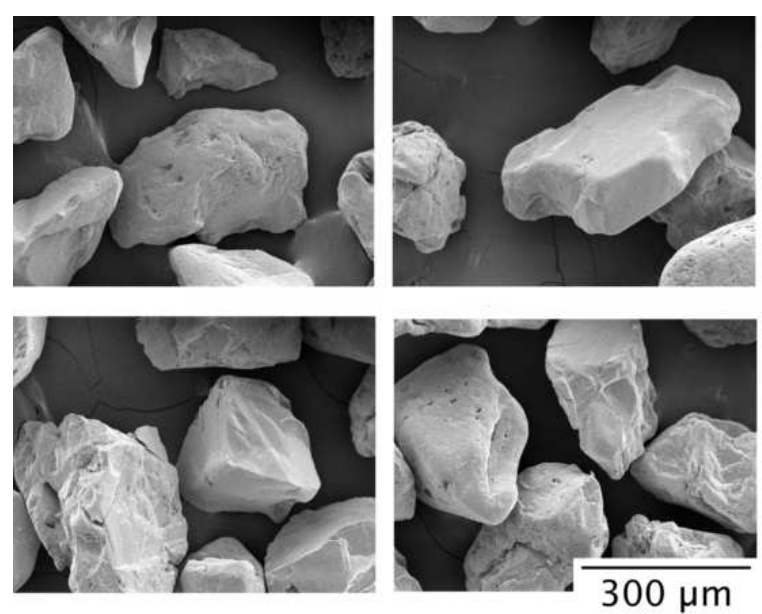

(b)

Figure 1: (a) Schematic illustration of the abrasion-test equipment, (b) SEM of the abrasive sand.

Table 3: ASTM G65-04 abrasion test parameters

\begin{tabular}{|c|c|}
\hline Wheel & Rubber-clad steel wheel \\
\hline Rubber & Chlorobutyl \\
\hline Hardness of rubber & Durometer A-60 \\
\hline Abrasive used & Silica sand, grade HR 30 (Prince Minerals, UK \\
\hline Mean particle size of silica sand & $300 \mu \mathrm{m}$ \\
\hline Hardness of silica sand & $956 \pm 22$ kgf-mm ${ }^{-2}(200 \mathrm{~g}$ load $)$ \\
\hline Rotational speed & 250 revolutions $\min ^{-1}$ \\
\hline Load & $130 \mathrm{~N}$ \\
\hline Sand flow rate & $300 \mathrm{~g} \mathrm{~min}^{-1}$ \\
\hline wheel diameter & $22.86 \mathrm{~cm}$ \\
\hline Total number of wheel revolution & 16200 \\
\hline Total sliding distance & $11.62 \mathrm{~km}$ \\
\hline
\end{tabular}

\section{Metallography Prior to Abrasion}

Fig. 2a shows the typical microstructure of pearlite. The mean true-spacing between the lamellae, $\bar{L}_{0}$, was measured by subjecting scanning electron micrographs to quantitative analysis. This involves the use of circular test grids, each of diameter $d_{c}$ [15]. The number $n$ of intersections with cementite lamellae yields the true spacing [16]:

$$
\bar{L}_{0}=\frac{\pi d_{c}}{2 n M} \quad \text { where } M \text { is the magnification }
$$

Using ten randomly selected locations $\bar{L}_{0}$ is found to be $85 \pm 7 \mathrm{~nm}$. Recent work has shown that the presence of cobalt in the steel helps achieve such a fine interlamellar spacing by increasing the driving force for transformation from austenite to pearlite [13].

Nanostructured bainite of the type studied here has been characterised thoroughly in previous work [17, 18], and many hundreds of images are available on archives [19]. Nevertheless, confirmatory transmission electron microscopy gives confidence that the right structure has been obtained, as shown in Fig. 2b,c where there are just two phases, the fine bainitic ferrite plates and the intervening films of austenite. The mean lineal intercept $(\bar{L})$ measured in the direction normal to the trace of the habit plane of the ferrite plates was measured at fifty randomly selected locations from transmission micrographs, 


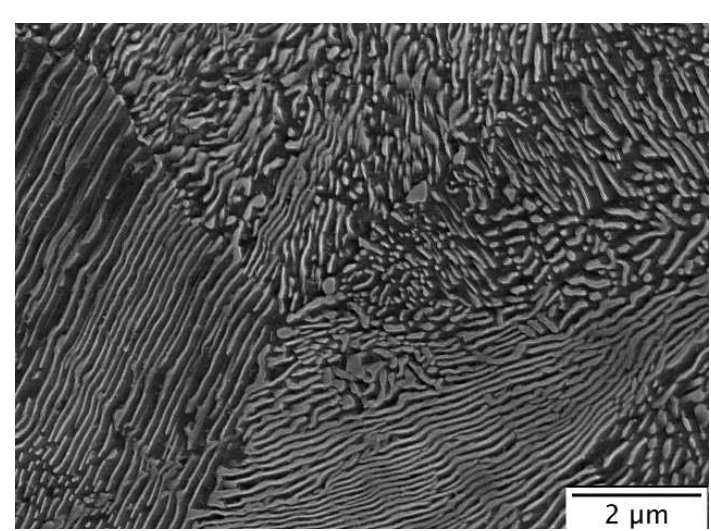

(a)

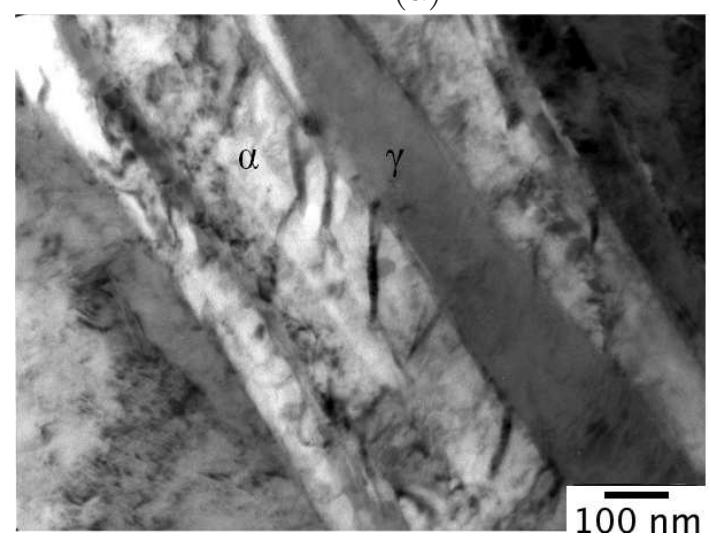

(c)

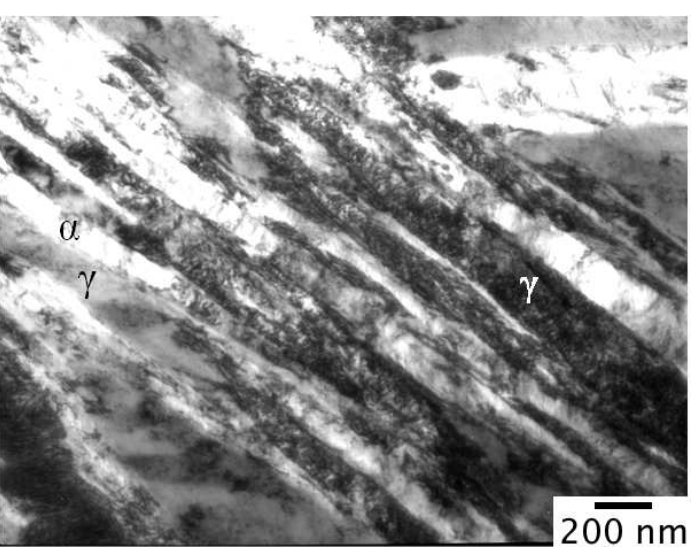

(b)

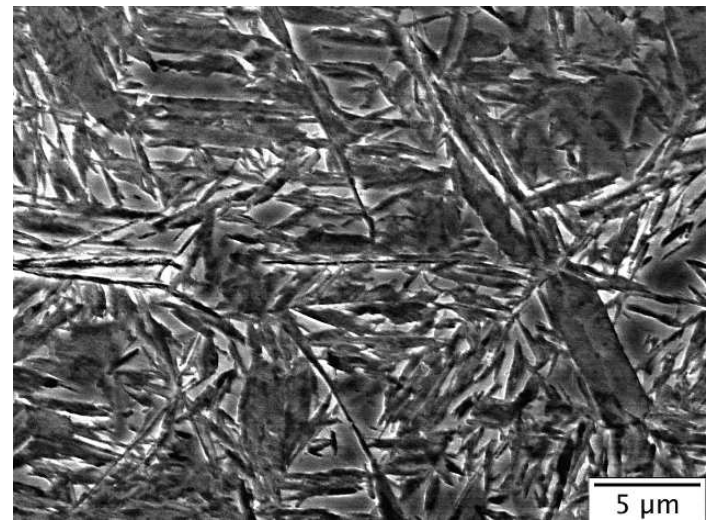

(d)

Figure 2: (a) Scanning electron micrograph of fine pearlite. (b) Mixture of bainitic ferrite and carbonenriched retained austenite, (c) higher magnification image of bainite, (d) martensite. 
in order to estimate the true thickness $(t)$ using the relation [20]:

$$
t=2 \bar{L} / \pi
$$

to be $54 \pm 4 \mathrm{~nm}$. In contrast, the martensite plates illustrated in Fig. $2 \mathrm{~d}$ are rather coarse, with islands of untransformed austenite in between.

\section{Results and Discussion}

\subsection{Abrasion test results and effect of hardness}

The volume losses measurements following 16200 cycles, corresponding to $\approx 11.62 \mathrm{~km}$ of sliding distance, are listed in Table 4, along with published data for comparison purposes. Although there are differences, the data show that the wear rate is not very sensitive to the structure of the steel studied, in spite of the substantial differences in hardness (Table 2). In fact the martensite, which is the hardest at $\approx 739 \mathrm{kgf}-\mathrm{mm}^{-2}$, shows the largest wear rate whereas the soft pearlite $\left(\approx 380 \mathrm{kgf}-\mathrm{mm}^{-2}\right)$ fares better. In all case, the specific wear rate observed in the present steel are significantly smaller than in the other the published data listed in Table 4; the notable exception is the richly-alloyed tool steel which can resist abrasion through the presence of large alloy carbides in the microstructure [21].

The present results are at first sight surprising given that the hardness is the most discussed parameter when it comes to abrasive wear resistance. This outcome cannot be attributed to correlations between hardness and wear failing because the microstructure is coarser than the grit size [22], since the latter is much coarser at $300 \mu \mathrm{m}$ than the length scales of any of the structures studied. However, it is necessary to distinguish between cases where the resistance is measured as a function of microstructure in the same steel, or for materials with similar microstructures but different compositions. In the latter case, a strong correlation is found between hardness and abrasive wear resistance as long as the size of the abrasive is much larger than the controlling scale of the microstructure [22]. For example, the wear resistance and hardness increase as the fraction of pearlite in a mixture with ferrite, becomes larger [22]. It is difficult to make comparisons because of experimental data are differently derived, but the variation in abrasive-wear rate seems greater when the pearlite fraction is changed by altering the carbon concentration of the steel [22-24], as opposed to when it is altered by changing the heat treatment for the same steel [25]. Nevertheless, the fact that in the present work, large variations in hardness do not lead to large differences in wear rate is inconsistent with published three-body tests reported on 4340 steel where about a $40 \%$ improvement was achieved in three-body abrasive wear resistance for a hardness increase of $325 \mathrm{kgf}_{-} \mathrm{mm}^{-2}$ [26].

A further possibility is that it is the mechanical properties of the work-hardened layer after the initial shakedown stage of abrasion that matter [25, 27, 28]. Cross sections of the abraded samples were polished, finishing with $200 \mathrm{~nm}$ colloidal silica for $5 \mathrm{~min}$ before nanoindenation. This is the standard preparation technique used in electron back scattered diffraction experiments to avoid surface damage effects. Nanoindentation hardness tests were then carried out in MTS nanoindenter using Berkovich indenter. The depth of penetration was kept constant at $\sim 400 \mathrm{~nm}$ for all the samples and hardness was derived from the load-displacement curves as in [29]. 
The results are shown in Fig. 3. The nanostructured bainite exhibits the greatest amount of surface hardening, to a maximum hardness of about $850 \mathrm{kgf}-\mathrm{mm}^{-2}$ and a depth which is greater than the size of the $\mathrm{SiC}$ particles. The martensite, on the other hand, shows considerable surface softening with the hardness unchanged after about $20 \mu \mathrm{m}$ of depth, a value much smaller than the size of the $300 \mu \mathrm{m}$ grit. The pearlite similarly shows a surface softened layer. The results are consistent with the bainite showing marginally better wear resistance than the martensite which has a greater bulk hardness, but the performance of pearlite still cannot be explained. These results, in combination with metallography, will be discussed later.

Table 4: Abrasive wear loss data of fine pearlite, nanostructured bainite and martensite

\begin{tabular}{lccc}
\hline Steel & $\begin{array}{c}\text { Hardness } \\
\left(\mathrm{kgf}-\mathrm{mm}^{-2}\right)\end{array}$ & $\begin{array}{c}\text { Specific wear rate } \\
\left(\mathrm{mm}^{3} \mathrm{~N}^{-1} \mathrm{~m}^{-1} / 0^{-5}\right)\end{array}$ & Reference \\
\hline Pearlite & 378 & 8.7 & \\
Bainite & 622 & 8.1 & \\
Martensite & 739 & 9.4 & {$[30]$} \\
Hardox500 & 530 & 12.7 & {$[31]$} \\
Stainless steel, type 304 & 164 & 91.1 & {$[31]$} \\
Low-alloy steel, ASTM A514 & 286 & 71.8 & {$[31]$} \\
Low-alloy steel, AISI 4340 & 560 & 39.6 & {$[31]$} \\
Tool steel, type D2 & 640 & 7.8 & {$[32]$} \\
Carbon steel, AISI 1060 & 795 & 17.2 & {$[32]$} \\
Armco Iron & 80 & 67.3 & {$[32]$} \\
AISI 1006 & 117 & 82.7 & {$[32]$} \\
AISI 1013 & 242 & 55.7 & \\
Hardox400 & 473 & 31.53 & 36.5 \\
Ground flat stock, tool steel & 830 & & \\
\hline
\end{tabular}

\subsection{Surface roughness}

The topographic contrast of the abraded surfaces of the pearlite, bainite and martensite are shown in Fig. 4. The blue represents troughs and the red portions are crests. The martensitic sample has the smoothest topography, followed by the pearlitic and bainitic samples. These results are consistent with the nanoindentation data (Fig. 3), where the bainite is seen to experience the deepest deformation. The data presented in Fig. 5 also show that the martensitic steel tends to develop wider and flatter grooves whereas those in the pearlitic and bainitic tend to be narrow and deep.

Scanning electron microscopy of the abraded surfaces qualitatively confirm the interferometry observations (Fig.6). The abraded pearlite exhibits both groove marks and a large number density of pits, similar to what had been reported elsewhere [28]. The grooves are of two kinds, wide ones delineated by ridges generated by plastic deformation, 


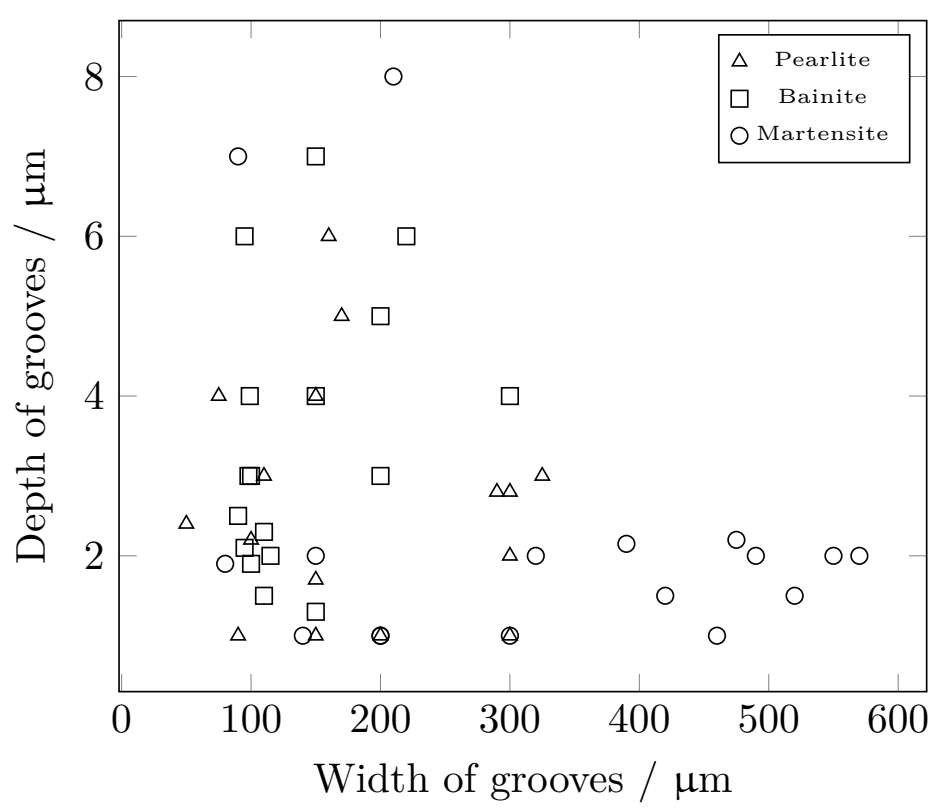

Figure 3: Nanoindentation hardnesses of microstructures along the depth away from the abraded surface after dry sand rubber wheel test.

and much narrower grooves. The pits are indicative of the obstacles to the motion of abrasive particles, causing the termination of some grooves at the pits. In contrast, the nanostructured bainite and martensite samples show much smaller and fewer pits.

\subsection{Sub-surface characterisation}

White-etching layers were found on the surfaces of all three microstructures studied, in contradiction of work presented in [33] where dry sand abrasion tests at $130 \mathrm{~N}$ load failed to produce such layers. Fig. 7a shows a thick and adherent featureless, white-etching layer. The featureless character is believed to be due to its extremely fine and probably severely deformed structure; there have been many mechanisms proposed for such layers, for example localised austenitisation followed by martensitic transformation and deformation $[28,34-37]$, but it is not the intention here to resolve these issues, but rather to highlight differences between the three kinds of sample. But it is notable that the nanoindentation tests presented earlier show a degree of softening rather than hardening. Indeed, the cementite lamellae are clearly plastically deformed in the abrasion direction (Fig. 7b), as is commonly observed in the severe deformation of pearlitic wires. It is possible that the layer reaches temperatures high enough to cause softening but not sufficient to cause austenitisation. The relatively soft initial hardness of the pearlite, and the softening of the abraded region implies that the white layer is relatively ductile and hence the displaced material remains attached to the surface, accounting for the low wear loss in the pearlitic sample.

The white-etching layer on the nanostructured bainite is thinner than that in the pearlitic sample, Fig.7c, and much harder than the underlying unaffected structure (Fig. 3). This could be attributed to the transformation of retained austenite into particularly hard martensite, since the former contains carbon concentrations in excess of $1.2 \mathrm{wt} \%$. However, a close examination of the white layer in Fig. 7c shows that it has undeformed plates indicating phase transformation after layer formation into martensite. 


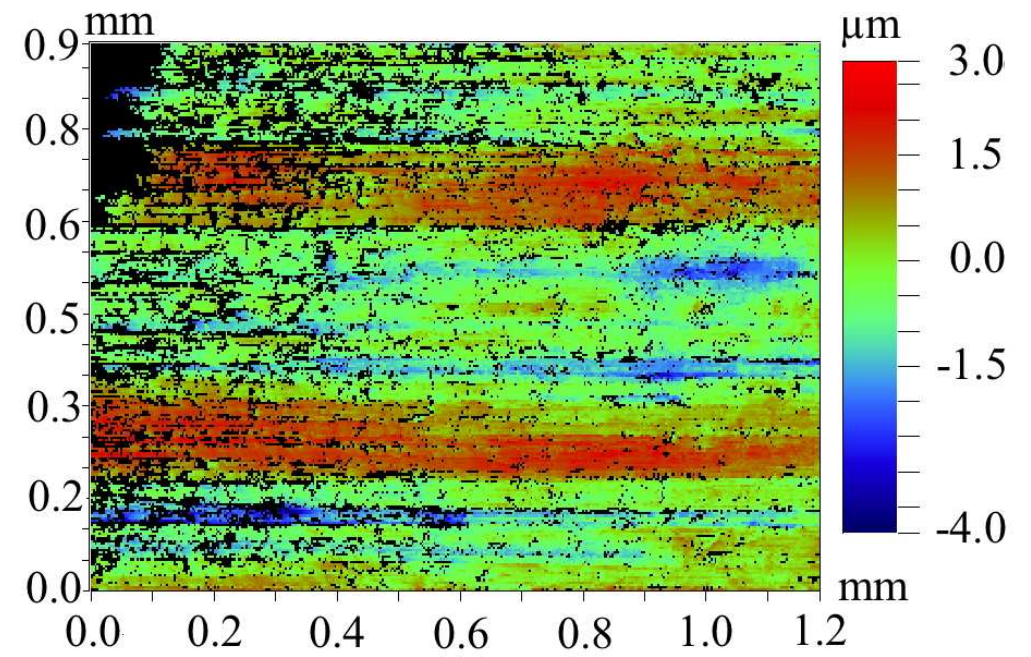

(a)

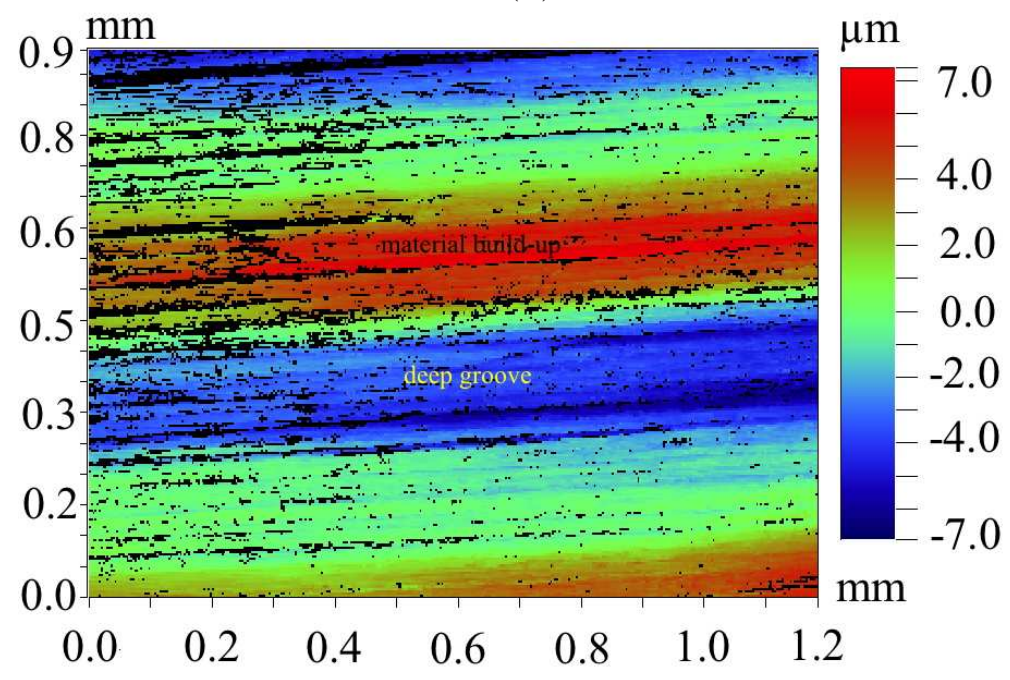

(b)

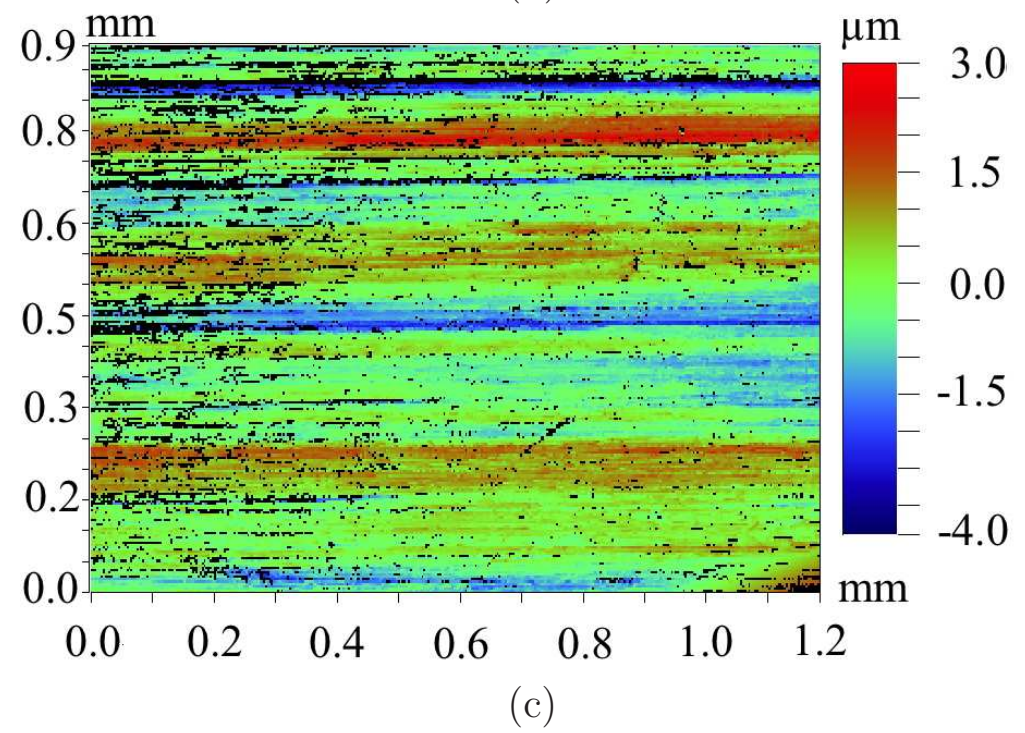

Figure 4: Interference micrographs of the abraded surfaces of (a) pearlite, (b) bainite and (c) martensite. Note that the colour scales are not all identical. 


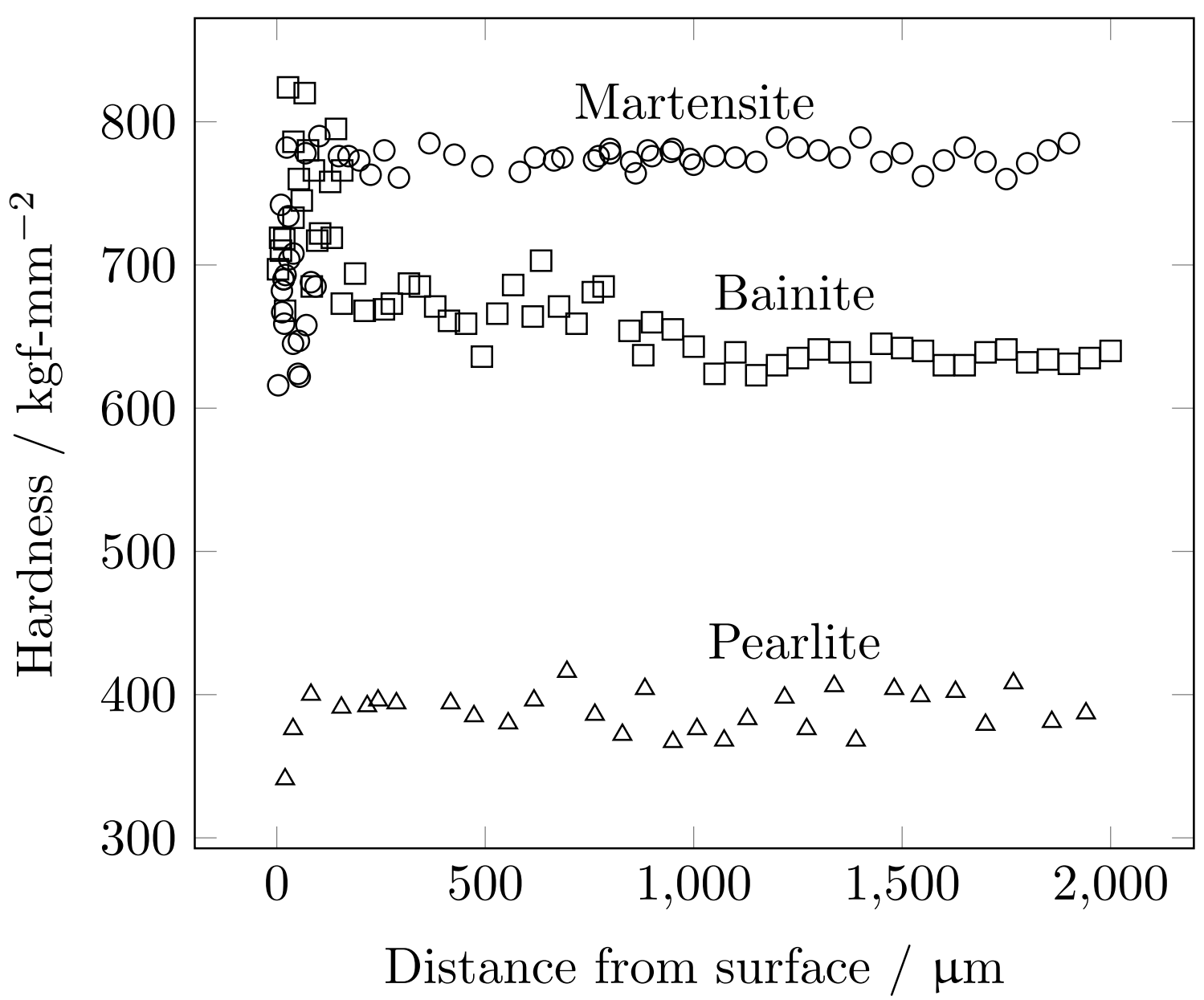

Figure 5: Groove characteristics for the three kinds of abraded samples.

This would imply that the region was reaustenitised by the intense deformation. Indeed, the hardness of the surface layer is consistent with that of the unaffected martensitic specimen (Fig. 3). Note that the plates cannot be bainite since that transformation is very slow. As with pearlite, substantial regions of the layer remain adherent to the surface.

In contrast, Fig. 7d of the martensitic transformation shows extensive fragmentation and hence the remaining white etching layer is considerably thinner than in the other samples. The fragments are not adherent to each other or to the surface and can be easily removed by the impact of sand particles, which may account for the relatively higher specific wear rate for martensite. The nanoindentation data show a softening at the surface, presumably the martensite tempering under the influence of deformation heat.

\subsection{X-ray diffraction}

X-ray diffraction was carried out before and after testing to identify any transformation of austenite at the abraded surface; the data are illustrated in Fig. 8 and the results of quantitative using full profile Rietveld analysis are listed in Table 5. There is no significant change in the austenite content of the martensitic specimen, presumably because the abrasion leads to a cutting action on the surface, leaving only a very thin layer of whiteetching material on the surface. In contrast, there is a large decrease in the case of the bainite, which could be interpreted as follows. The bainite clearly undergoes severe 


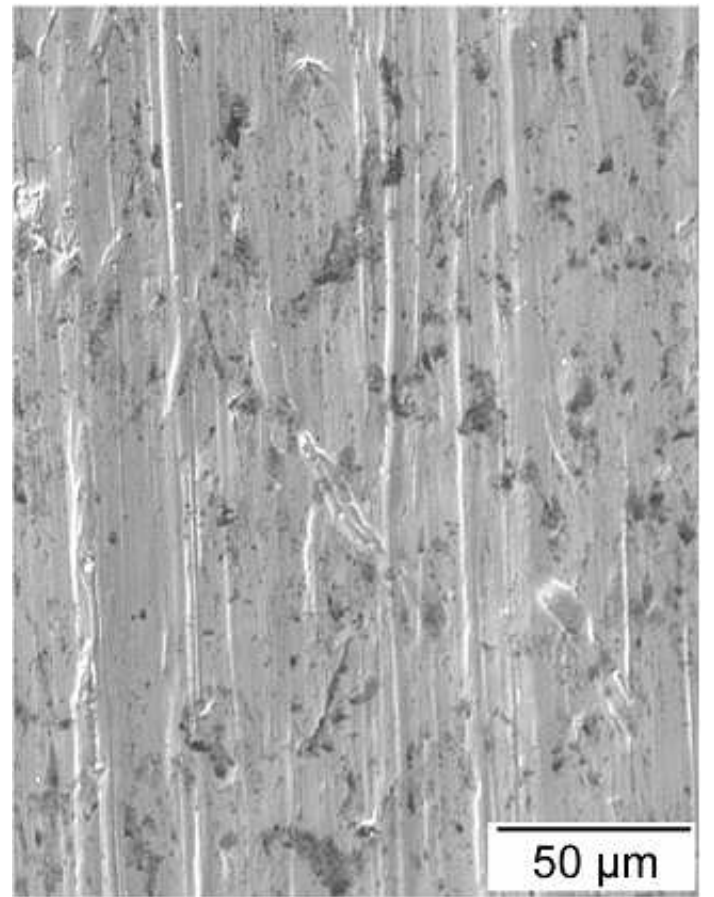

(a)

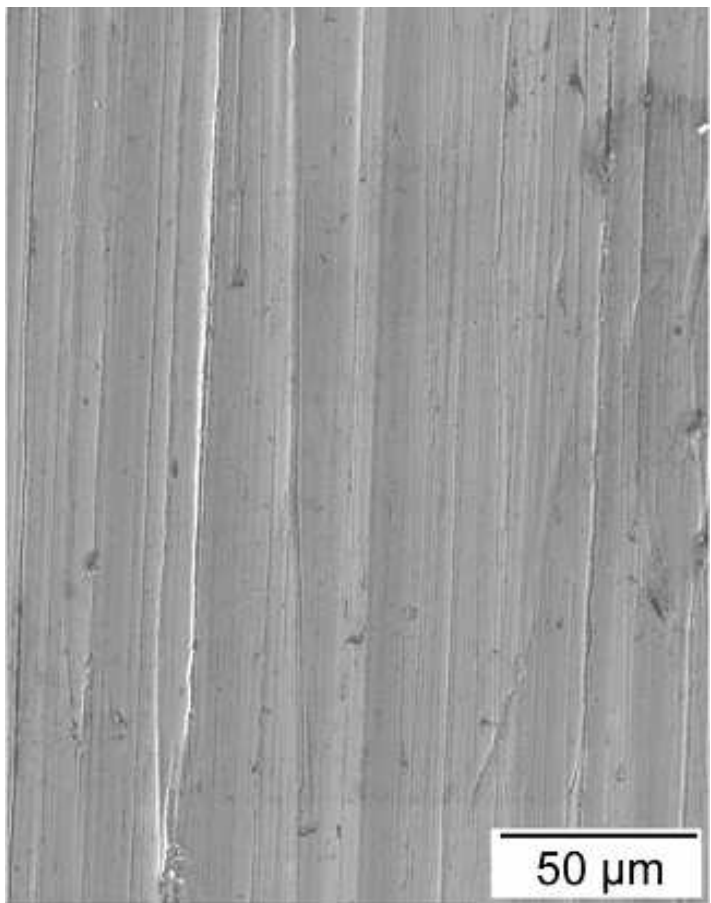

(b)

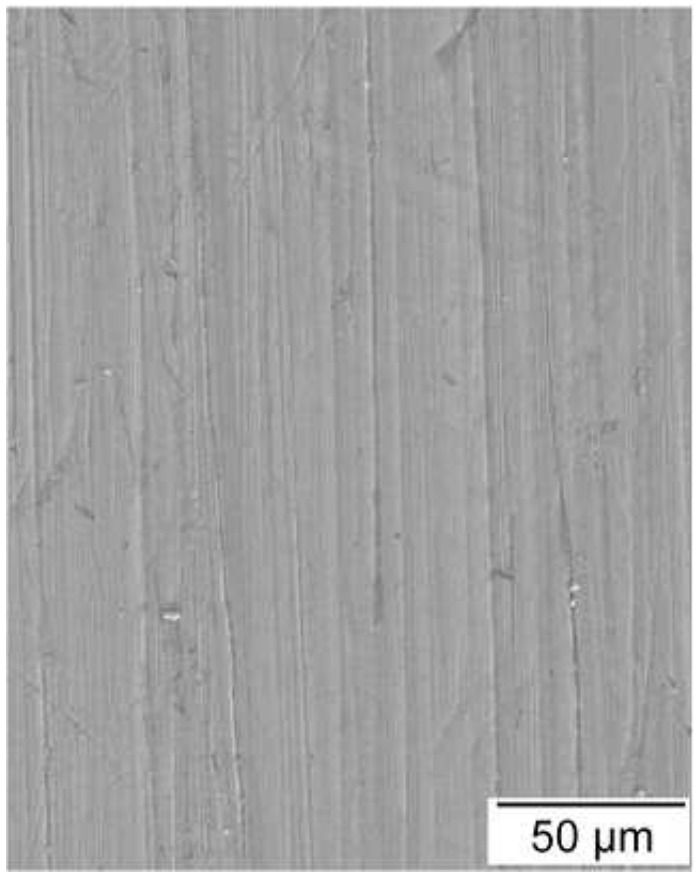

(c)

Figure 6: Secondary electron micrographs of the abraded surface of (a) pearlitic, (b) bainitic and (c) martensitic samples. 


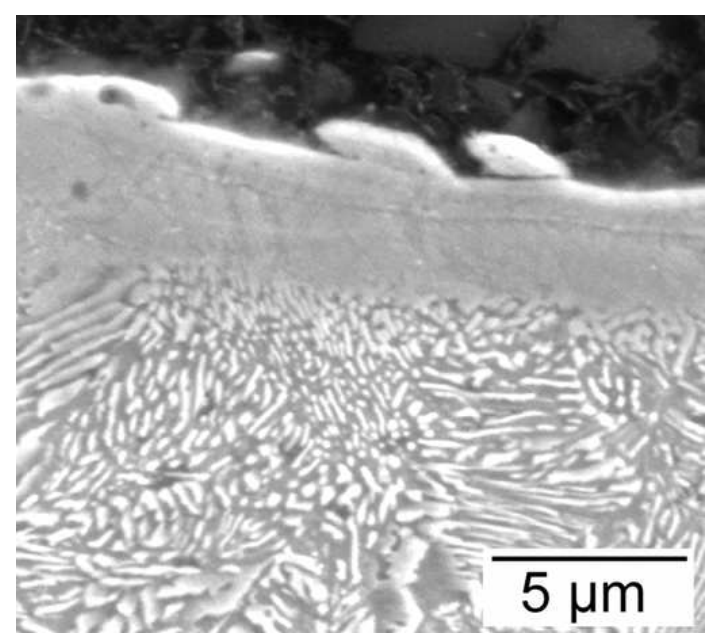

(a)

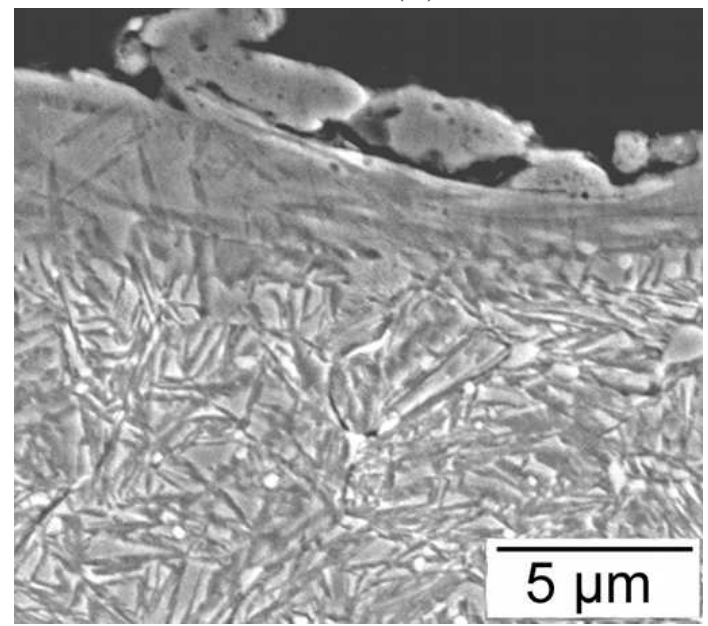

(c)

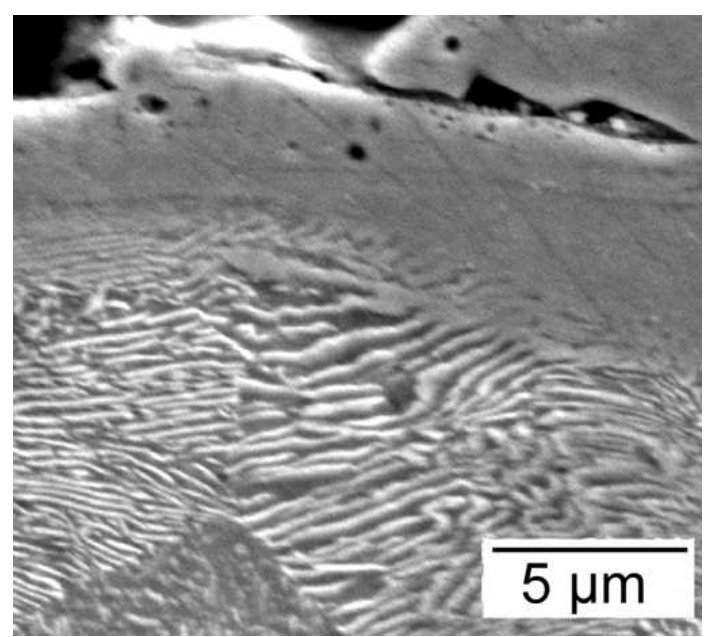

(b)

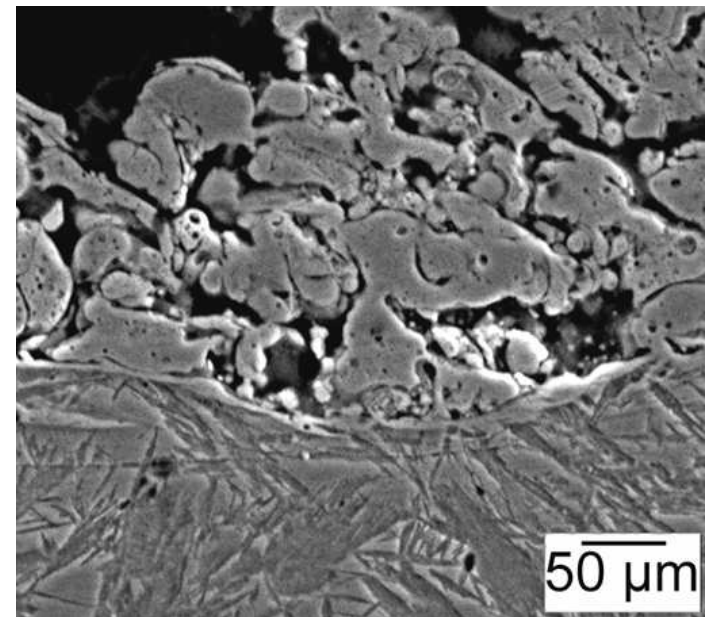

(d)

Figure 7: Sub-surface observations. (a) Pearlite: thick, continuous white etching layer. (b) Pearlite: severe deformation of the pearlite lamellae near white etching layer. (c) Bainite, showing a thin, continuous white-etching layer. (d) Martensite, showing a discontinuous layer with evidence of chip formation. 
deformation and if the interpretation of Fig. 7c is correct, then this deformation causes austenitisation followed by martensitic transformation. This would leave a smaller amount of retained austenite, and as Table 5 shows, the quantity left $(12 \pm 3 \%)$ is not dissimilar to that expected from a directly quenched martensitic sample $(17 \pm 4 \%)$.

Table 5: X-ray diffraction analysis by full pattern Rietveld refinement.

\begin{tabular}{lc}
\hline Microstructure & Austenite volume \% \\
\hline Martensite, before abrasion & $17 \pm 4$ \\
Martensite, after abrasion & $16 \pm 4$ \\
nanostructured bainite, before abrasion & $44 \pm 3$ \\
nanostructured bainite, after abrasion & $12 \pm 3$ \\
\hline
\end{tabular}

\section{Summary and Conclusions}

The somewhat unexpected outcome for the steel studied, is that there is not much of a variation in the abrasion data in spite of the large differences in hardness between the three structures (fine pearlite, nanostructured bainite, and untempered martensite) that have been studied. Within the small differences in the measured wear rate, the hardest phase martensite has the greater wear rate, whereas pearlite better resists abrasion. A clear transition is observed from the sliding of particles in the harder samples, to stopping and pitting in the case of the pearlite, as has been observed in previous studies [26, 32, 38-40]. Nanostructured bainite has the largest resistance to abrasion and is the only structure found to harden at the surface, possibly because of austenitisation of the surface layer during the course of abrasion. The bainite wears by a combination of grooving and relatively minor pitting, whereas in the case of the hard martensite it is the cutting that dominates. Furthermore, martensite suffers from greater fragmentation at the surface, and hence exhibits the largest weight loss. This presumably is a reflection of the brittle nature of high-carbon martensite, and the clean removal of material from the surface is consistent with the fact that the austenite content at that location does not change. The bainite shows the most interesting behaviour, with minimal pitting, a large change in retained austenite content and the minimum wear rate under the experimental conditions reported here.

The following conclusions may be reached from these studies:

1. Experiments have been conducted in which a novel steel designed for the large scale production of nanostructure, has been transformed instead into fine pearlite, nanostructured bainite, and coarse untempered martensite. These three conditions differ greatly in hardness, but lead only to small changes in the three-body abrasive wear tests conducted using silica. In all cases, the abrasive wear resistance is superior to many steels available commercially or reported in research publications. 


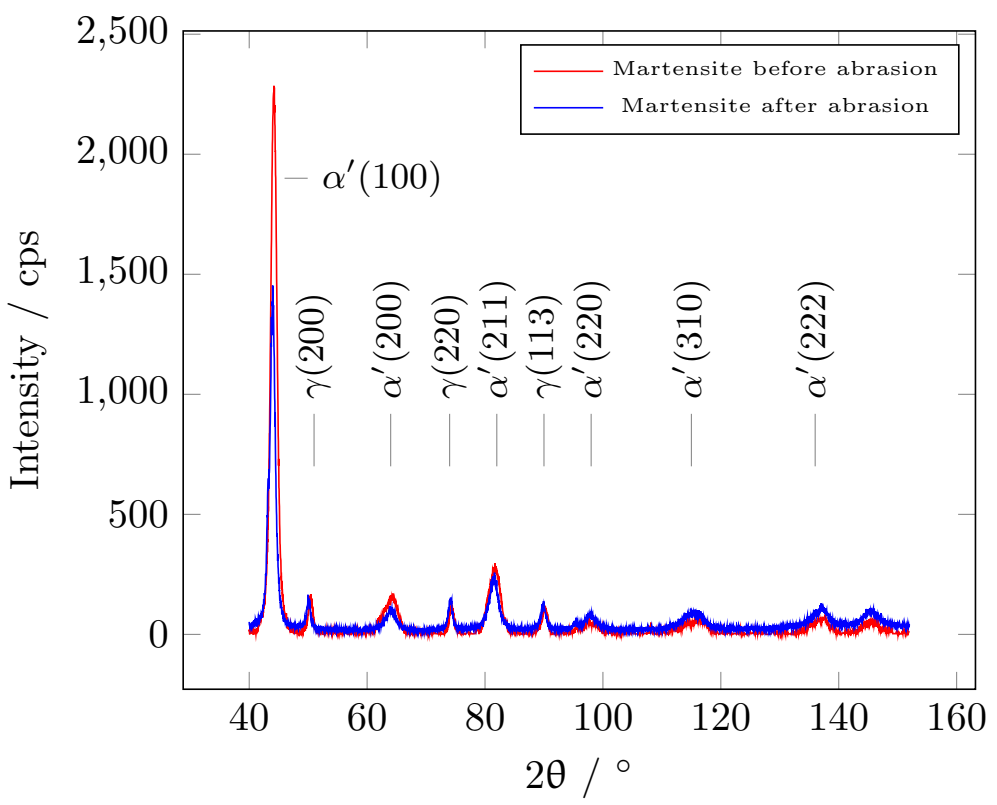

(a)

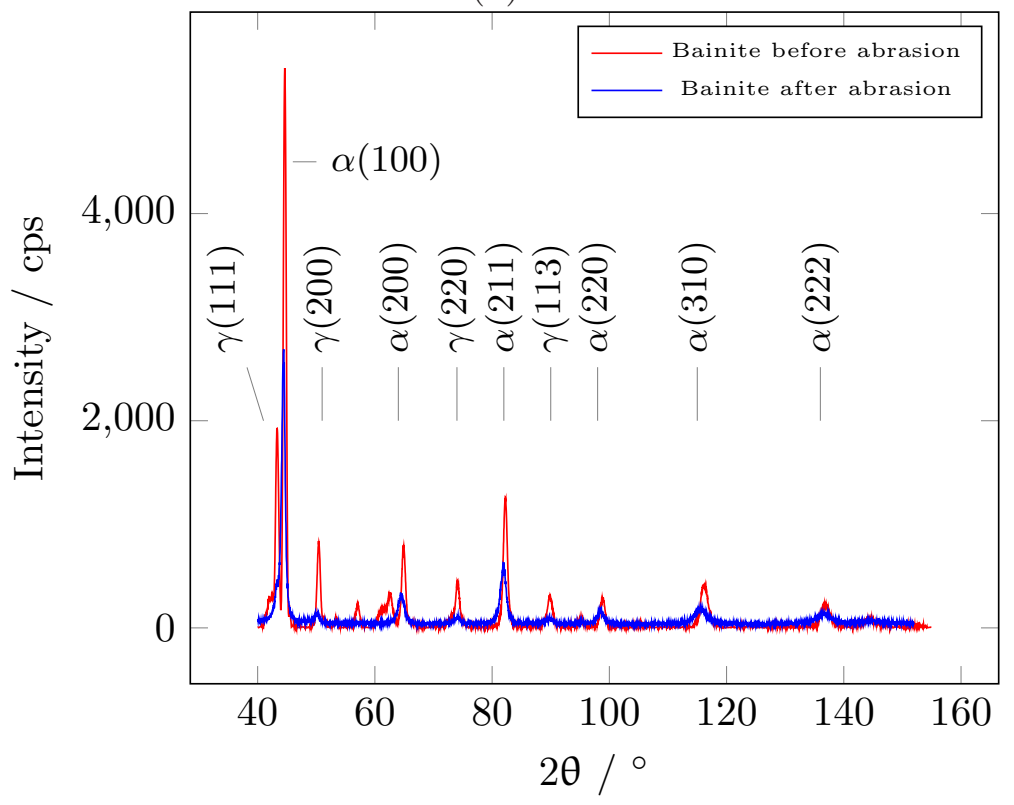

(b)

Figure 8: X-ray diffraction spectra before (red) and after (blue) abrasion. (a) Martensite. (b) Bainite. 
2. The insensitivity of the wear resistance to structure is because different mechanisms of surface damage operate in each case. In the case of pearlite, the abrasive particles slide and are sometimes halted in their progress, leading to extensive pitting. Fragmentation of the surface is the mechanism for the untempered martensite, with very little affected material adhering to the steel surface. Like pearlite, there is significant plastic deformation at the active surface of bainite, with good adhesion of the damaged material.

3. Nanoindentation tests show that only the bainitic structure is hardened at the surface, and there are indications that reaustenitisation occurs, with subsequent martensitic transformation which causes hardness levels to increase. Both the pearlitic and martensitic samples show significant softening in the abraded surface regions.

Acknowledgements: We thank Tata Steel Limited for generously funding this project, to the Welding Alloys Group for assistance with the abrasion tests and to Dr. Mathew Peet, Lucy Fielding and Dr. Ayan Bhowmick for helpful discussions. 
[1] F. G. Caballero, H. K. D. H. Bhadeshia, K. J. A. Mawella, G. G. Jones, P. Brown, Mater. Sci. Technol. 18 (2002) 279-284.

[2] H. K. D. H. Bhadeshia, P. Roy. Soc. Lond. A. Mat. 466 (2010) 3-18.

[3] H. K. D. H. Bhadeshia, Sci. Technol. Adv. Mater. (2013) In Press.

[4] H. K. D. H. Bhadeshia, ISIJ Int. 41 (2001) 621-640.

[5] T. S. Wang, J. Yang, C. J. Shang, X. Y. Li, B. Lv, M. Zhang, F. C. Zhang, Surf. Coat. Tech. 202 (2008) 4036-4040.

[6] P. Zhang, F. C. Zhang, Z. G. Tan, T. S. Wang, L. H. Qian, Wear 271 (2011) 697-704.

[7] J. Yang, T. S. Wang, B. Zhang, F. C. Zhang, Wear 282-283 (2012) 81-84.

[8] A. Leiro, E. Vuorinen, K. G. Sundlin, B. Prakash, T. Sourmail, V. Smanio, F. G. Caballero, C. G. Mateo, R. Elvira, Wear 298-299 (2013) 42-47.

[9] C. G. Mateo, F. G. Caballero, ISIJ Int. 45 (2005) 1736-1740.

[10] H. K. D. H. Bhadeshia, Mat. Sci. and Tech. 21 (2005) 1293-1302.

[11] H. K. D. H. Bhadeshia, D. V. Edmonds, Met. Sci. 17 (1983) 420-425.

[12] R. A. Jaramillo, S. S. Babu, G. M. Ludtka, R. A. Kisner, J. B. Wilgen, G. MackiewiczLudtka, D. M. Nicholson, M. Murugananth, H. K. D. H. Bhadeshia, Scr. Mater. 52 (2004) 461-466.

[13] K. M. Wu, H. K. D. H. Bhadeshia, Scr. Mater. 67 (2012) 53-56.

[14] ASTM G65-04, standard test method for measuring abrasion using the dry rubber wheel apparatus,ASTM international, No 03.02, West Conshohocken, Pennsylvania, USA.

[15] E. E. Underwood, Quantitative Stereology, Addison-Wesley, Reading, MA, 1970.

[16] S. A. Saltykov, Stereometric Metallography, Metallurgizat, Moscow, 2nd edition, 1958.

[17] F. G. Caballero, H. K. D. H. Bhadeshia, Curr. Opin. Solid St. M. 8 (2004) 251-257.

[18] H. K. D. H. Bhadeshia, P. Roy. Soc. Lond. A. Mat. 466 (2010) 3-18.

[19] H. K. D. H. Bhadeshia, Archive of micrographs,http://www.msm.cam.ac.uk/phasetrans/2005/bulk.html, 2005.

[20] L. C. Chang, H. K. D. H. Bhadeshia, Mater. Sci. Tech. 11 (1995) 874-881.

[21] P. Koshy, R. C. Dewes, D. K. Aspinwall, J. Mater. Process. Tech. 127 (2002) 266-273.

[22] M. A. Moore, Wear 28 (1974) 59-68.

[23] R. C. D. Richardson, Wear 10 (1967) 291-309.

[24] P. L. Hurricks, Wear 26 (1973) 285-304. 
[25] J. Larsen-Badse, K. G. Mathew, Wear 14 (1069) 199-206.

[26] A. Misra, I. Finnie, Wear 85 (1983) 57-68.

[27] O. Vingsbo, S. Hogmark, Fundamentals of friction and wear of materials, ASM, Metals Park, OH, 1981.

[28] B. K. Prasad, S. V. Prasad, Wear 151 (1991) 1-12.

[29] W. C. Oliver, G. M. Pharr, J. Mater. Res. 19-1 (2004) 3-20.

[30] S. Kondapally, Personal communication, Welding Alloys UK, 2011.

[31] J. A. Hawk, R. D. Wilson, J. H. Tylczak, O. N. Dogan, Wear 225-229 (1999) 10311042 .

[32] S. M. Nahvi, P. H. Shipway, D. G. McCartney, Wear 267 (2009) 2083-2091.

[33] L. Xu, S. Clough, P. Howard, D. StJohn, Wear 181-183 (1995) 112-117.

[34] M. A. Moore, Wear 17 (1971) 51-58.

[35] O. Scheffier, C. Allen, Trib. Int. 21-3 (1998) 127-135.

[36] K. M. Mashloosh, T. S. Eyre, Tribol. Int. 18 (1985) 259-266.

[37] A. L. Wingrove, J. Aust. Int. Met. 16-1 (1971) 67-70.

[38] Y. L. Wang, Z. S. Wang, Wear 122 (1988) 123-133.

[39] L. Fang, Q. D. Zhou, J. J. Li, Wear 151 (1991) 313-321.

[40] S. Das, B. K. Prasad, A. K. Jha, O. P. Modi, A. H. Yegneswaran, Wear 162-164 (1993) 802-810. 